\title{
Elementary rocket Launch II
}

\author{
Judy Schieble \\ Spaceport Sheboygan \\ Elementary Rocket Chair
}

\begin{abstract}
The Elementary Rocket Launch Program is sponsored by Spaceport Sheboygan. Spaceport Sheboygan is a knowledge center of interactive science / space exhibits, programs for students and the public. Through hands-on activity of rocket construction for students develop teamwork and critical thinking skills; applying STEM concepts.
\end{abstract}

\section{Program Background}

The elementary rocket launch has been a lead-up program to rocketry using space to teach science and math concepts. The program is offered to $4^{\text {th }} \& 5^{\text {th }}$ graders in the Sheboygan County during the month of May. We have added a 2-station tracking component to emphasize a math component to the program. A drawing of the students' rocket flight was generated from the data collected from the rocket's launch. Students received a picture, showing the direction and height of his / her rocket a week after the event.

We introduced bottle rocketry a couple of years ago as one of the options the student could participate in at the elementary rocket launch. Some of the students did both the bottle and model rocket construction. The scheduling of the students to do both in the event was a little difficult. As a committee, we decided to make the bottle rocket component a separate event. Thus, it would allow students do both and concentrate on them separately.

For two years, $\mathrm{a}-5^{\text {th }}$ grade teacher at Oostburg Elementary has been doing a week long, 2-liter plastic bottle rocket unit in her science curriculum. She has created her own data sheet for the students to collect their data. This teacher has introduced critical thinking and teamwork for her students into this unit. I have assisted this teacher every year in this week - long bottle rocket unit.

\section{Program Evaluation}

The Elementary Rocket Launch program has been successful over a decade allowing $4^{\text {th }} \& 5^{\text {th }}$ graders of the Sheboygan County to construct model rockets, launch them and see how high they go. Over the years we experienced a declined in a number of students, but we are pleased with the inclusive quality of science and math components. 
We have added a larger model rocket for the $5^{\text {th }}$ graders; thus the student who chooses to participate as a $4^{\text {th }} \& 5^{\text {th }}$ grade would be building 2 different rockets. Enhancing the quality of the program, we have the optical 2-station tracking for $6^{\text {th }}$ graders to utilize to collect the data. This math component adds to the STEM part of the program.

Putting the Bottle rocket program as a separate component to the program gave the elementary rocket program a new direction as we placed it in the classroom. It gave the teachers a chance to place it in their science curriculum. Even with a set of directions, the students came up with many different designs for the rocket. Thus, the technology and engineering components of STEM incorporated. The teacher constructed data sheets for the students to collect: pressure, angle of the launch, and results of each flight. Due to the results, the teacher emphasized to the student, that only one variable was changed on each launch or trial.

As of this year, we had 5 new teachers include the bottle rocket activity in their science curriculum. So, that gives us total of 6 elementary / middle school teachers who are using space to teach science. I assisted each teacher on the rocket construction day and the launch day. Those new teachers only did it one or two days and worked on one goal: either distance or accuracy.

One new component that was added to the Elementary rocket program was the straw rocket launcher activity. The straw rocket would be used at the lower elementary grades where the teacher can implement it as a class activity or student group work. The amount of the time available in their school year and the level of the students determined which way the class went.

The straw rocket activity allows the teacher and the students to apply STEM in any degree. Two, second grade teachers did it as a class- activity. The teacher constructed the straw rocket, generated the activity and the students helped collect and complied the data of the experiment. Three $4^{\text {th }}$ grade teachers discussed the concepts of force, motion and engineering with their classes. Students were then given the materials to design their rocket and predict their results on their data sheets.

After the students conducted and collected their data, a graph of their data was generated. Bases on their data, the teacher then changed one variable and the students had to predict the results. Using critical thinking and analysis of the data, most students were correct on the outcome of the straw rocket's flight.

A third piece of equipment was purchased with the grant money, a tripod bottle rocket launcher. Due to the short time left in the school year, only one $5^{\text {th }}$ grade teacher was able to experiment with the bottle launcher. The purpose of this equipment was to see the different parts of the 'flight of the rocket'; including being able to deploy the parachute of the rocket, after the rocket has reached 'apogee' in 
its flight. The variables that were used in the other bottle rocket unit can still be addressed here.

At the middle school grades, the class can calculate average acceleration for the flight of the rocket. This concept would have to be mastered in the class and practiced in sample problems before it is applied to this activity. The students should be aware of other factors as it affected the data collected.

\section{Future Outcomes}

For the Elementary Model Rocket program, we would like to extend the $5^{\text {th }}$ grade portion of the program to offer a 'payload' rocket as well as just a level II rocket kit. The $5^{\text {th }}$ grade student would design a payload for his/her rocket, launch the rocket and see the results of his / her design. Optical tracking would be measured.

As for the straw and bottle rocket activities, we would like to hold teacher workshops at Spaceport Sheboygan. Our goals would be to instruct teachers in the use of the equipment in their science curriculum, to review which teaching standards are covered and how they are mastered in the activity.

We would work with the beginning activities, discussing how the activity can be changed to incorporate upper level knowledge, critical thinking skills and other disciplines. Teachers, who would be new to this kind of activity, will become comfortable with this kind of hands-on learning activity, going on to experience success with their students. Experienced teachers will fell confident about taking the activity to a higher level of learning, meeting state standards and integrating it with other disciplines. 